\title{
Factors and Objectives of Sustainable Development at the Implementation of Digital Technologies and Automated Systems in the Mining Industry
}

\author{
Alexander Myaskov ${ }^{1}$, Igor Temkin $^{1}$, Sergey Deryabin ${ }^{1}$, and Dora Marinova ${ }^{2}$ \\ ${ }^{1}$ NUST MISIS, College of Mining, 119991, Leninsky av., Moscow, Russia \\ ${ }^{2}$ Curtin University, Sustainability Policy Institute, 6102 Kent St, Bentley WA, Australia
}

\begin{abstract}
Mining inevitably violates the natural environment. The consequences of its functioning for the environment are diverse at different stages of the life of the enterprise. During mineral exploration, environmental damage is generally negligible, localized, and can be relatively easily repaired. Subsequent initial work, both with open pit and underground mining methods, has a more significant impact on the environment, but still less significant than with the development itself. During extraction and enrichment, the main production process, the most noticeable consequences are violation of land resources, pollution by wastewater, changes in hydraulic regime and composition of atmospheric air. The key factor, of course, is not how much land is used for any particular activity, but whether this use can be compatible with maintaining environmental integrity.
\end{abstract}

\section{Introduction}

Despite the fact that about 30 years ago the concept of sustainable development was officially approved, the current economic activity of humankind obviously contributes to environmental degradation and the planet's resources. As a concept, environmental friendliness of society is so attractive that it has become a unifying topic of both scientific research and political decisions, but at the same time, populist speculative discussions about environmental policy and technological innovations.

At the modern, already largely digital, mining enterprise, which are still one of the largest environmental pollutants, there is still no consensus on what should be supported, first of all, at the expense of potential environmental protection funds. events. Even despite a noticeable level of geoecological and ecosystem researches, noting the environmental impact of the mining industry. Without a clear understanding of the effects, greening the activities of industrial enterprises will remain for a long time a slogan that has little practical value for owners of enterprises investing in their own profit, rather than meeting the common millennium development goals, recently formulated by the $\mathrm{UN}$ and presented as global trends in the development of humankind. 


\section{A modern mining enterprise and environment}

Mining and mineral processing create several types of solid waste: overburden rocks moving to gain access to a mineral deposit; waste rock separated from ore during mining; and waste formed during the enrichment process. In the absence of water, these solid wastes cause mainly aesthetic damage to the environment and, under certain climatic conditions, affect the dustiness of adjacent areas [1-5]. When existing mining wastes interact with surface or groundwater, they can become a source of acid pollution, which is a very serious environmental problem of mining and enrichment. The nature and extent of actual environmental damage caused by solid waste and acid pollution varies significantly from case to case, depending on a number of factors.

Mining and enrichment technologies are important: underground mining per unit of product produced produces much less waste than in open cast mining, but significantly affects the change in the hydro regime of the area. The higher the degree of extraction during enrichment, the smaller the number of tails [6-11]. But perhaps the more reagents are involved in the process, which in turn causes damage.

The climate is important: in arid regions, there is little water needed to create acid pollution, in the Arctic regions there are specific features of water use and the binding of chemical elements.

The location and population density are important: the pollution of water that enters drinking water sources not only destroys the ecosystem and affects biodiversity, but also harms human health.

Finally, environmental management practices in mining companies are important: approaches to land reclamation, restoration of disturbed lands, hydrological measures, the possibility of using water treatment technologies, digitalization of processes to minimize general pollution and increase the efficiency of automated equipment.

Consequently, "sustainable" production has two aspects: firstly, it is necessary to find an appropriate balance between the benefits of mining and related losses from the production process; and secondly, which is more important and will allow combining the goals of the owners (maximum efficiency) and the goals of mankind (maximum environmental friendliness), it is necessary to develop new digital automated projects and products for mining and processing minerals in order to reduce both production costs and environmental damage.

At the moment, such a symbiosis is possible at all stages of the operation of the enterprise from drilling to processing.

\section{Factors and objectives of sustainable development in the implementation of digital technologies in mining enterprises}

At first glance, sustainability and mining are in conflict. Mining removes limited resources from nature and, consequently, leads to environmental degradation, and more specifically, subsoil. But there are a number of factors that make mining quite acceptable in terms of developing the concept of sustainability.

First, in the process of exploration and development, mining companies are constantly updating and increasing their reserves. Current reserves represent only a small fraction of the mineral resources remaining in the earth's crust. Technological advances in exploration increase the speed of discovery of mineral deposits and at the same time reduce the cost of exploration. Exploration and development leads to the discovery and exploration of previously unknown mineral deposits and, possibly, equally important resources at existing natural and technogenic deposits. 
Secondly, technological changes, increasing digitalization, are developing opportunities for mining. Technological improvements in the extraction and processing of minerals reduce costs and ensure profit for investors, and, accordingly, interest in introducing the most effective, including from an environmental point of view, technologies.

Thirdly, even when the mine is physically depleted, the processing of waste rocks formed from previous redistributions can, more often, be considered as a continuation of primary mining. In fact, recycling is an important source of many new resources.

Fourth, when mining ceased, if the corresponding part of the income was invested in human capital and the social sphere, wonderful new projects could appear that would provide completely new opportunities. This PostMining concept has been very successfully implemented in Germany and the UK. But this is a separate topic for discussion.

In order to actively increase production efficiency due to the introduction of modern digital technologies, automated and robotic systems, it is possible to determine the development directions of mining enterprises with mandatory consideration of geoecological, ecosystem and global environmental trends in general, it is necessary to clearly define the most important aspects of environmental friendliness mining development.

Task 1. Development of the best scientific base for a deep inventory of mineral resources. An important need is the development of a better methodology for identifying resources that are not used in modern economic conditions with known technologies, but which may become economically feasible in other conditions. The fact that mineral resources are located not only in several different ranges of concentration or concentration, but also in different chemical states, in completely different natural formations (permafrost, oceans, industrial waste) will significantly expand expectations about the possibility of developing new deposits, forming more careful and rational use of resources.

Task 2. Implementation of a tough global policy on environmental management. This requires a clear, structured global agenda on the benefits and fines for implementing mining projects, taking into account the current millennium goals and, at the same time, the personal effects of specific investors.

Task 3. Inclusion of the concept of deep processing and reuse in the concept of sustainability of enterprises. Ultimately, recycling should play a crucial role in the use of natural materials, and form a pool of successful projects on problems and disposal methods.

Task 4.Using BigData for better data on the environmental consequences of mining, on the costs of complying with environmental standards, and on best practices for environmental management of mining. Most opinions about mining and its environmental impact are based on unofficial and partial information. In addition, much is based on past practices that are currently changing annually. The lack of information about both environmental damage and compliance costs makes it difficult to determine whether existing practices are consistent. Finally, systematic data on best practices in environmental management will provide a standard with which to compare current and future performance of individual companies.

Task 5. Use the results of fundamental science to improve environmental management and restoration ecology associated with the extraction and processing of minerals. One aspect of this problem is the development of "environmental digital" models of ore deposits. Mineral exploration is guided by traditional models of ore deposits, geological representations of specific types of deposits, designed to help predict where and how mining should take place. Environmental digital models will expand existing models to include the characteristics of ore and associated gangue in terms of environmental risks, geoecological and ecosystem aspects. It is also advisable here to impose a digital double of future technological processes, simulating possible consequences taking into account the above. 


\section{Conclusion}

The concept of caring for the Planet encourages scientists to collect data and develop ideas to help create public policy in the field of mining. States should promote activities that support the introduction of state-of-the-art aggregates and approaches that promote both efficient mining and the most environmentally friendly way. At the same time, when developing environmental guidelines and regulations, the state should help ensure the flexible and achievement of the goals set by private investors or the state itself.

Each of the presented tasks is facilitated by various modern technologies implemented at the largest mining companies in the world. Forming automated complexes, rock mass transfers, new approaches to enrichment or drilling and blasting operations, all companies are guided by environmental standards that are currently in force. With the large introduction of digital technologies in the design process of mining, setting the environmental friendliness of the process, taking into account the factors of sustainability of economic indicators, the mining industry can easily meet the established Millennium Development Goals.

\section{Acknowledgement}

This work is supported by the Russian Science Foundation under grant 19-17-00184

\section{References}

1. A.B. Efremenkov, A.A. Khoreshok, S.A. Zhironkin, A.V.Myaskov, IOP Conference Series: Earth and Environmental Science, 50(1), 012009 (2017)

2. I.O. Temkin, A.V. Myaskov, I.S. Konov, S.A. Deryabin, Gornyi Zhurnal, 11, 82-86 (2019)

3. V.I. Efimov, S.M. Popov, T.V. Korchagina, N.V. Efimova, Gornyi Zhurnal, 12, 91-94 (2017)

4. A.L. Ivannikov, C. Kongar-Syuryun, J. Rybak, Y. Tyulyaeva, IOP Conference Series: Earth and Environmental Science, 362:1, 012130 (2019)

5. V.V. Moseykin, A.M. Galperin, V.V. Cheskidov, S.A. Punevsky, Gornyi Zhurnal, 12, 82-86 (2017)

6. C.R. Carter, D.S. Rogers, International Journal of Physical Distribution and Logistics Management, 38(5), 360-387 (2008)

7. P. Bansal, Strategic Management Journal, 26(3), 197-218 (2005)

8. J. Prno, D. Slocombe, Resources Policy, 37(3), 346-357 (2012)

9. L. Haibin, L. Zhenling, Resources, Conservation and Recycling, 54(12), 1331-1340 (2010)

10. D. Laurence, Journal of Cleaner Production, 19(2-3), 278-284 (2011)

11. A.M. Esteves, Resources Policy, 33(1), 39-47 (2008) 